\title{
WILMS' TUMOR GENE 1 (WT1) EXPRESSION IN CHILDHOOD ACUTE LYMPHOBLASTIC LEUKEMIA
}

\author{
Mohamed A. Badr*, Tamer H.Hassan*, AsmaaM.Esh**,Wesam A. Mokhtar*. \\ *Departement of pediatrics, Faculty of medicine ,Zagazig university,**Department of clinical \\ pathology, Faculty of medicine ,Zagazig university.
}

\begin{abstract}
Aim \&Objectives: Wilms tumor 1 (Wt1) gene is over expressed in majorty of acute leukemia.The aim of this study is to evaluate(WT1) gene expression in children with acute lymphoblastic leukemia and to find out the relationship between it and other morphological, immunophenotypic and prognostic factors.

Subjects \&Methods:An case-control study was conducted in pediatric Hematology \& oncology unit ,zagazig university children's hospital ,zagazig university during the period of January 2011 to June 2013.we examined the level expression of (WT1) gene in 44 newly diagnosed children with acute lymphoblastic leukemia and 20 controls patient with hematological problems other than hematological malignancies. A fresh peripheral blood samples were collected patients and controls and submitted to RNA extraction, reverse transcription of extracted RNA and real-time quantitive PCR.

Results:we detect a wide range of $\mathrm{Wt} 1$ gene expression level among 44 patients of acute lymphoblastic leukemia. Statistically, Wt1 gene expression level was significantly higher in T-cell acute lymphoblastic leukemia than in B-cell Precursor acute lymphoblastic leukemia $(\mathrm{P}<0.001)$ and also higher in those with expression of myeloid marker than those without expression of these markers. Analysis of relapsed cases (3/44) indicated that abnormally increase of wt 1 gene expression level was associated with increased risk of relapse.

Conclusion: This study suggest that Wt1 expression in childhood acute lymphoblastic leukemia is very variable and much more expressed in t cell leukemia than BCP ALL and show higher levels in relapsed patients thus indicating a possible prognostic marker of childhood acute lymphoblastic leukemia.

Keywords:(Wt1) gene, childhood, acute lymphoblastic leukemia.
\end{abstract}

\section{INTRODUCTION}

W ilms' tumor gene 1 (WT1) is an embryonic zinc-finger transcription factor, which was originally identified as a tumor suppressor gene inactivated in Wilms' tumors [1].WT1is located on chromosome $11 \mathrm{p} 13$ and encodes a zinc finger transcription factor. Post-transcriptional mRNA modifications and the presence of possible several transcription initiation sites give rise to a number of different WT1 protein isoforms (at least 32) that are localized in specific subcellular and subnuclear regions and show different, partially overlapping but distinct functions [2-5]

In normal tissue, WT1 is expressed during embryogenesis where it plays a pivotal role in the development of the urogenital tract [6,7].Alterations of WT1 expression (both underor overexpression) have been described in a number of malignancies and premalignant syndromes. Remarkably, WT1 overexpression has been found in $80-90 \%$ of acute myeloid leukemia (AML) and $70-90 \%$ of acute lymphoblastic leukemia (ALL) patients, with an even higher frequency at relapse [8,9]. WT1overexpression was also detected in the cerebrospinal fluid of patients with B-ALL where it showed a strong association with disease relapse[10].
The majority of acute leukemias express the normal, wild-type WT1 gene. In addition, point mutations

and small deletions or insertions may also occur and have been identified in approximately $10-20 \%$ of acute leukemias, predominantly in biphenotypic and AML, but rarely in ALL. In AML, these alterations were shown to be associated with an unfavorable prognosis[2,3,11].

In this study, we focused on evaluation of WT1 expression and its clinical implications in prognsis of childhood ALL, where WT1 has been least studied and its impact remains most controversial.

\section{Samples}

\section{MATERIALS AND METHODS}

Patients samples :After ethical committee approval and informed consent, diagnostic PB samples from 44 patients with childhood ALL( from Hematology \& oncology unit, zagazig university children hospital, zagazig university)were collected on a consecutive basis from decemder 2011 to june 2013 and analyzed. The male represent $52.3 \%$,female represent $47.7 \%$; the median age was 3.9 years(range 2-12years).

They involved 36 B-cell precursor (BCP) ALL, 3 BCP ALL with aberrant expression of myeloid markers 5 T-cell ALL.The main risk 
factors defined as age $<1$ or $>10$ years and $\mathrm{WBC}>50 \times 10^{3}$ at diagnosis were present in2, 3and 7 patients, respectively. Patients were treated according to standard protocols(CCG protocol) The median follow-up is 9.5 months (range 1-28); during this period 3 of the 44 patients relapsed, and 5 patients died.

\section{Controls samples:}

To evaluateWT1expression in normal hematopoietic tissues, peripheral blood samples obtained after informed consent from 20 patients with haematological problems other than haematological malignancies were examined .The control group was selected to match the patient group in sex and age.

\section{Methods}

Sample processing:

PB were collected into sterile tubes with anticoagulant (K3 ,EDTA) and immediately transported to the lab at room temperature. The initial processing of the samples was performed within $12 \mathrm{~h}$ after their collection, in most cases within the first $4 \mathrm{~h}$. RNA was isolated from the samples using an RNeasy Mini Kit (Qiagen,Roche,Germany), and the concentration of extracted RNA was evaluated by spectrophotometry (Nanodrop 2000 thermoscintific) .The cDNA synthesis was performed using the High Capacity cDNA Reverse Transcription Kits(Applied, Biosystems ,USA.) starting from lug of total RNA.

\section{Real time quantitive-PCRfor WT1gene}

RQ-PCR for the detection and the quantification of WT1 was developed using ( ipsogen WT1 ProfileQuant Kit, QIAGEN,GERMANY ,cat.no.67692) and the TaqMan ${ }^{\circledR} \quad$ Universal PCR Master Mix,NoAmpErase ${ }^{\circledR}$ UNG (Applied Biosystems, Forster City, CA). As a control gene (CG), ABL was detected in all samples without BCR-ABL translocation. The RQ-PCR reaction was performed Applied Biosystems 7500 Real-Time PCR System. For WT1 and CG the threshold was set at 0.1 to be in the exponential phase. The WT1 and CG copy number and WT1 normalized copy number (NCN, WT1/ABL copies) were calculated according to the standard curve method. Standard curves were created using plasmid DNA calibrators - ABL Control Gene Standards (Ipsogen).

\section{Administrative design and Ethical issues:}

An official permission from Zagazig University, Faculty of medicine was taken to pediatric hematology and oncology unit. The title and objectives of this study was explained to them to insure their cooperation. The head of the pediatric hematology and oncology unit was informed about the nature and steps of the study and written consent was taken. The study group was informed about the nature and the purpose of the study. The study group was not exposed to any harm or risk. Patient's data was confidential.

\section{Statistical analysis of the recorded data:}

The collected data were computerized and statistically analyzed using SPSS program (Statistical Package for Social Science) version 16. For the statistical calculations, data coding was done, and Qualitative data were represented as frequencies and percentages, Chi-square test $\left(\mathbf{x}^{2}\right)$, Mc Nemartest was carried out for testing the association between the qualitative data whenever possible. Quantitative data were compared using Analysis Of Variance (F test), Kruskall Wallis test and paired $t$ test. The test results were considered significant when $\mathrm{p}$-value $<\mathbf{0 . 0 5}$.

\section{RESULTS}

\section{WT1 expression in normal PB}

WT1 expression was detected in all control samples (normal PB).

Table (1) Wt1 gene expression in patients and controls:

\begin{tabular}{|c|c|c|c|c|c|}
\hline & & Patients & controls & $\begin{array}{c}\text { Man } \\
\text { test }\end{array}$ & $\begin{array}{c}\mathbf{P} \\
\text { value }\end{array}$ \\
\hline \multirow{3}{*}{$\begin{array}{c}\text { WT1 gene } \\
\text { expression } \\
\text { (NCN x } \\
10)\end{array}$} & median & $\mathbf{5 0 . 7}$ & 0.121 & \multirow{3}{*}{$\begin{array}{l}M= \\
650\end{array}$} & \multirow[t]{3}{*}{ 0.00* } \\
\hline & $\begin{array}{l}\text { Mean } \\
\pm \text { SD }\end{array}$ & $265.0 \pm 391.5$ & $\begin{array}{c}0.12 \pm \\
0.07\end{array}$ & & \\
\hline & Range & 0.15-1827 & $\begin{array}{c}0.02- \\
0.23\end{array}$ & & \\
\hline
\end{tabular}

This table shows that $\mathrm{Wt} 1$ gene expression is significantly higher in patients than controls.

\section{WT1 expression in childhood ALL}

WT1 overexpression was found in most of the childhood T-ALL cases, of median 895and range 785-1827 and inBCP ALL, WT1 expressed of median21.3 and range 0.15-785 .In BCP ALL with aberrant expression of myeloid markers WT1 expressed of median 620and range 553-750.

Table (2) Wt1 gene expression in relation to immunophenotyping:

\begin{tabular}{|c|c|c|c|c|c|c|}
\hline & & $\begin{array}{l}\text { T cell } \\
\text { ALL }\end{array}$ & $\begin{array}{l}\text { BCP } \\
\text { ALL }\end{array}$ & $\begin{array}{l}\text { BCP ALL } \\
\text { with } \\
\text { aberrant } \\
\text { expression } \\
\text { of myeloid } \\
\text { markers }\end{array}$ & $\begin{array}{c}\text { ANO } \\
\text { VA } \\
\text { test }\end{array}$ & $\begin{array}{c}\mathbf{P} \\
\text { value }\end{array}$ \\
\hline 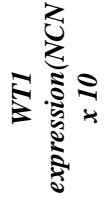 & 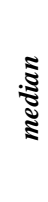 & 895 & 21.3 & 620 & 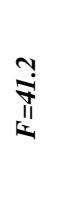 & $\stackrel{*}{8}$ \\
\hline
\end{tabular}




\begin{tabular}{|c|c|c|c|}
\hline $\begin{array}{l}\text { ज } \\
+1 \\
\stackrel{+1}{\Xi} \\
\Xi\end{array}$ & $\begin{array}{c}107 \\
0 \pm 4 \\
25.6\end{array}$ & $\begin{array}{c}121 \\
6 \pm 20 \\
3.2\end{array}$ & $\begin{array}{c}641 \pm 10 \\
0.2\end{array}$ \\
\hline$\stackrel{\Xi}{E}$ & $\begin{array}{c}785 \\
- \\
182 \\
7\end{array}$ & $\begin{array}{l}0.15 \\
-785\end{array}$ & $553-750$ \\
\hline
\end{tabular}

This table shows that Wt1 gene expression was signifiantly higher in patients with T cell ALL than that with BCP ALL and is also significantly higher in patients with BCP ALL with expression of myliod markersthan that without expression of myeloid markers.

WT1 expression in childhood ALL and the risk of relapse

Wt1 gene expression in relapsed cases(3/44)shows median of 785 and range 411860.that is differ from remaining cases in remission that was of median 21.3 and range 0.15 1827 .statistically, there was higher statistically significance of wt1 gene expression in relapsed patient than patient in remission, $(\mathrm{P}=0.01)$.

\section{DISCUSSION}

Although promising, the significance of WT1 as a prognostic factor and a possible target for immunotherapy in acute leukemia still remains unclear, and the role of WT1 in the process of leukemogenesis is not well understood. To elucida the WT1 expression patterns and its clinical implications in childhood ALL, we established a reliable assay for WT1 detection and quantification, and using this studied WT1 in a representative group of controls and childhood ALL patients. In the vast majority of leukemia cases, the abnormality inWT1 expression is only of a quantitative character. Therefore, an exact method that enables sensitive detection with precise, preferably absolute quantification of WT1 is a necessary prerequisite for WT1 analysis in acute leukemia. It is probable that the inconsistent methodology contributed most of all to the discrepant results of some studies To evaluate the normal background WT1 expression, we analyzed WT1 in control samples - PB from control patient.

WT1 is physiologically expressed in normal hematopoietic cells. The WT1 expression has been well studied in CD34 hematopoietic precursors, where WT1 may reach levels similar to those found in leukemic cells[12,13].Except for very early Investigations, [14] ,WT1 expression has been identified in normal BM and PSC controls or CD34 concentrates in all further studies, either in a proportion[15,16,17,18] or all[19,20,21] of the samples tested. WT1 expression in normal PB has not been specifically studied and the function of WT1 in PB cells is not known. While some authors did not find any WT1 expression in normal $\mathrm{PB}[14,22,23,24,18]$ others detected the presence of WT1 in a proportion of samples $[30,37,43,45]$. We found variable levels of WT1 in all PB samples analyzed, which may reflect a higher sensitivity of our method

.With respect to the normal ranges of WT1 expression, we analyzed WT1 in a representative group of childhood ALL patients. In childhood BCP-ALL, we detected a very wide range of WT1 expression levels with an important difference of interest; ALL blasts with aberrant co-expression of myeloid markers, were associated with a significantly higher WT1 expression level than blasts without co-expression of myeloid markers.

Contrary to BCP-ALL, most of the childhood T-ALL patients showed WT1 over expression, with the median being significantlyhigher than in BCP-ALL patients .Several studies matched with our results[26,27,28]

In previous studies, WT1 over expression above the normal values was found in the majority or all of the ALL samples $[14,15,16,17,19,22,24,29,30]$ and WT1 expression in acute leukemia below the ranges of normal controls was never detected. Most of the studies did not distinguish between Band T-ALL; in those analyzing these subtypes separately,controversial results were found, with higher WT1 overexpression detected in B-ALL in some of them[31] and in T-ALL inothers.[29] However, these studies investigated WT1 mostly inadult ALL patients or in heterogenous groups of children and adults, $[14,17,19,22,32]$ in PB samples, $[22,24]$ using potentially less sensitivePCR techniques of WT1 detection [1,16,17,29,30,32] and with a limited number or type of normal controls tested.[14,30,32].

Recent studies have identified WT1 overexpression as an independent adverse prognostic factor in acute leukemia ssociated with an increased risk of relapse.[23,17,18 ]

Among our childhood ALL patients there was a trend toward higher WT1expression in those who relapsed and this reached statistical significance. But insufficient number of relapsed caes may be the weakest point in these results.

\section{CONCLUSION}

The current management of childhood ALL relies on patient stratification and risk-directed therapy based on prognosticfactors and initial 
response evaluation, recently including minimal residual disease monitoring. Although the system of risk assessment as well as the techniques of MRD detection are well established and the treatment outcome is excellent, with70-80\% of patients achieving long-term remission, molecular aberrations that could act as new prognostic factors, MRD markers and therapeutic targets are investigated with the aim to improve further the prognosis of patients with childhood ALL.Among these, WT1 is one of the most promising. The role of WT1 in leukemogenesis is yet to be defined but in an increasing number of studies, WT1 overexpression has been identified as apotential independent adverse prognostic factor in acute leukemia, a suitable marker for MRD monitoring, mainly in AML, and a promising target for immunotherapy in leukemia and other malignancies.

Our study showed that WT1 expressionin childhood ALL is very variable and, in general, much lower than in AML or adult ALL. Thus, WT1 will not be a useful marker for MRD detection in childhood ALL. But like in other types of acute leukemia, also, childhood ALL patients with WT1 overexpression have an increased risk of relapse, and WT1 overexpression represents a potential additional independen strisk factor in childhood ALL. Interestingly, a proportion of childhood ALL patients express WT1 in levels below the normal physiological BM WT1 expression, and this WT1 under-expression also seems to be associated with an increased risk of relapse. These results only support the complex model of WT1 regulatory effects in normal and malignant hematopoiesis.Further studies, both functional and clinical, will be necessary to clarify the WT1 expression patterns and functions in acute leukemia.

\section{REFERENCES}

1. Haber DA, Housman DE (1992) Role of the WT1 gene in Wilms' tumour. Cancer Surv 12:105-117.

2- Sugiyama H. Wilms' tumor gene WT1(2001)its oncogenic function and clinical application Int J Hematol; 73: 177-187.

3- Sugiyama H. (2002) Wilms tumor gene WT1 as a tumor marker for leukemic blast cells and its role in leukemogenesis. Methods Mol Med; 68: 223-237.

4-Scharnhorst V, van der Eb AJ, Jochemsen AG. (2001) WT1 proteins: functions in growth and differentiation. Gene; 273: 141-161.

5-Menssen HD, Renkl HJ, Rodeck U, Maurer J, Notter M, Schwartz Set al. (1995) Presence of
Wilms' tumor gene (wt1) transcripts and the WT1nuclear protein in the majority of human acute leukemias.Leukemia; 9: 1060-1067.

6-Pritchard-Jones K (1999) The Wilms tumour gene, WT1, innormal and abnormal nephrogenesis.PediatrNephrol 13(7):620-625.

7- Kreidberg JA (1996) Gene targeting in kidney development. Med Pediatr Oncol27(5): 445452 . doi:10.1002/(SICI)1096-911X (199611)27:5\&lt;445::AIDMPO10\&gt;3.0.CO; 2-9.

8- Sugiyama H. (1995)Wilms tumor gene (WT1) as a new marker for thedetection of minimal residual disease in leukemia. Leuk Lymphoma1998; 30: 55-61.

9- Ostergaard M, Olesen LH, Hasle H, Kjeldsen E, Hokland P. WT1gene expression (2004)an excellent tool for monitoring minimal residual disease in $70 \%$ of acute myeloid leukaemia patients - results froma single-centre study. $\mathrm{Br}$ J Haematol; 125: 590-600.

10-Ramirez O, Linares A, Trujillo ML, Caminos JE. (2003)WT1 mRNA incerebrospinal fluid associated with relapse in pediatric lymphoblastic leukemia. Pediatr Hematol Oncol; 25: 453-458.

11-Menssen HD, Siehl JM, Thiel E. (2002) Wilms tumor gene (WT1)expression as a pan leukemic marker. Int Hematol; 76:103-109.

12- 20 Ellisen LW, Carlesso N, Cheng T, Scadden DT, Haber DA. (2001) TheWilms tumor suppressor WT1 directs stage-specific quiescenceand differentiation of human hematopoietic progenitor cells. EmboJ; 20: 1897-1909.

13- Hosen N, Sonoda Y, Oji Y, Kimura T, Minamiguchi H, Tamaki Het al.(2002) Very low frequencies of human normal CD34+haematopoieticprogenitor cells express the Wilms' tumour gene WT1 atlevels similar to those in leukaemia cells. $\mathrm{Br} \mathrm{J}$ Haematol 116:409-420.

14-Menssen HD, Renkl HJ, Rodeck U, Maurer J, Notter M, Schwartz Set al. (1995)Presence of Wilms' tumor gene (wt1) transcripts and the WT1nuclear protein in the majority of human acute leukemias.Leukemia; 9: 1060-1067.

15- Inoue K, Ogawa H, Sonoda Y, Kimura T, Sakabe H, Oka Y et al.(1997)Aberrant over expression of the Wilms tumor gene (WT1) in humanleukemia. Blood; 89: 1405-1412.

16-Kletzel M, Olzewski M, Huang W, Chou PM (2002).Utility of WT1 as a reliable tool for the detection of minimal residual disease inchildren with leukemia. PediatrDevPathol; 5: 269-275. 
17-Garg M, Moore H, Tobal K, Liu Yin JA. (2003) Prognostic significance ofquantitative analysis of WT1 gene transcripts by competitivereverse transcription polymerase chain reaction in acute leukaemia.Br J Haematol; 123: 49-59.

18-Barragan E, Cervera J, Bolufer P, Ballester S, Martin G, Fernandez Pet al. (2004)Prognostic iplications of Wilms tumor gene (WT1)expression in patients with de novo acute myeloid leukemia. Haematologica; 89: 926933.

19-Cilloni D, Gottardi E, De Micheli D, Serra A, Volpe G, Messa Fet al (2002). Quantitative assessment of WT1 expression by real timequantitative PCR may be a useful tool for monitoring minimalresidual disease in acute leukemia patients. Leukemia; 16:2115-2121.

20- Ellisen LW, Carlesso N, Cheng T, Scadden DT, Haber DA. (2001) The Wilms tumor suppressor WT1 directs stage-specific quiescenceand differentiation of human hematopoietic progenitor cells. EmboJ; 20: 1897-1909.

21- Ogawa H, Tamaki H, Ikegame K, Soma T, Kawakami M, Tsuboi A ,et al. (2003) the usefulness of monitoring WT1 gene transcripts for theprediction and management of relapse following allogeneic stemcell transplantation in acute type leukemia. Blood; 101:1698-1704

22-Kreuzer KA, Saborowski A, Lupberger J, Appelt C, Na IK, le CoutreP et al. Fluorescent 50-exonuclease assay for the absolutequantification of Wilms' tumour gene (WT1) mRNA: implicationsfor monitoring human leukaemias. $\mathrm{Br} \mathrm{J}$ Haematol 2001; 114:313-318.

23-Trka J, Kalinova M, Hrusak O, Zuna J, Krejci $\mathrm{O}$, Madzo $\mathrm{J}$ et al.Real-time quantitative PCR detection of WT1 gene expression in children with AML: prognostic significance, correlation withdisease status and residual disease detection by flow cytometry.Leukemia 2002; 16: 1381-1389.

24-Magyarosy E, Varga N, Timar J, Raso E. Follow-up of minimalresidual disease in acute childhood lymphoblastic leukemia byWT1 gene expression in the peripheral blood: the Hungarian experience.Pediatr Hematol Oncol 2003; 20: 65-74.

25-Uzunel M, Jaksch M, Mattsson J, Ringden O, Brune M, JohanssonJE et al. (2003) Minimal residual disease detection after allogeneic stemcell transplantation is correlated to relapse in patients with acutelymphoblastic leukaemia. Kinetics of minimal residual disease andchimerism in patients with chronic myeloid leukemia afternonmyeloablative conditioning and allogeneic stem cell transplantation. $\mathrm{Br} \mathrm{J}$ Haematol; 122: 788-794

26-Inoue K, Ogawa H, Sonoda $\mathrm{Y}$ et al (1997) Aberrent over-expression of Wilms tumor gene (WT1) in human leukemia. Blood 89(4):14051412.

27- CilloniD,Saglio G(2004) WT1 as auniversal marker for minimal residual disease detection and quantification in myeloid leukemias and in myeloid dysplastic syndrome.ActaHaematol 11291-2):7984.doi:10.1159/000077562.

28-Im HJ,KongG, Lee H (1999) Expression of wilms tumor gene (WT1) in children with acute leukemia. Pediatr HaematolOncol 16(2) :109118.doi:10.1080/088800199277434.

29-Ozgen U, Anak S, Ozbek U, Sarper N, Eryilmaz E, Agaoglu L et al. (2000)wt1 gene expression in childhood acute leukemias. ActaHaematol; 103: 229-230.

30- Gaiger A, Linnerth B, Mann G, Schmid D, Heinze G, Tisljar K et al. (1999)Wilms' tumour gene (wt1) expression at diagnosis has noprognostic relevance in childhood acute lymphoblastic leukaemiatreated by an intensive chemotherapy protocol. Eur J Haematol; 63: 86-93.

31-Niegemann E, Wehner S, Kornhuber B, Schwabe D, Ebener U. (1999)wt1gene expression in childhood leukemias. Acta Haematol;102: 72-76.

32- Inoue $\mathrm{K}$, Ogawa $\mathrm{H}$, Sonoda $\mathrm{Y}$, Kimura $\mathrm{T}$, Sakabe H, Oka Y et al. (1997)Aberrant overexpression of the Wilms tumor gene (WT1) in humanleukemia. Blood; 89: 1405-1412. 